\title{
Cholestatic Effect of Intraperitoneal Administration of Tryptophan to Suckling Rat Pups
}

\author{
RUSSELL J. MERRITT, FRANK R. SINATRA, DONABY HENTON, AND HARRY NEUSTEIN \\ Departments of Pediatrics and Pathology, Childrens Hospital of Los Angeles, University of Southern California \\ School of Medicine, Los Angeles, California 90054
}

\begin{abstract}
Summary
The potential cholestatic effect of amino acids and metabolites of tryptophan were evaluated by use of seven daily intraperitoneal injections to suckling and weanling rat pups. Of the amino acids present in parenteral nutrition solutions, only tryptophan (given at a dose of $4 \mathrm{mM} / \mathrm{kg})$ produced a significant $(p<0.01)$ elevation of serum cholylglycine $(12.8 \pm 1.0 \mu \mathrm{M} /$ liter $)$ as determined by radioimmunoassay, compared to $4.9 \pm 0.4 \mu \mathrm{M}$ /liter in salinetreated control animals. Total serum conjugates of cholic acid, as determined by radioimmunoassay, were similarly elevated, as was serum alanine aminotransferase. Tryptophan injection resulted in elevated cholylglycine concentrations only at doses of 3 $\mathrm{mM} / \mathrm{kg} / \mathrm{day}$ or higher. Animals more than 2 weeks old did not demonstrate elevation of serum cholylglycine. Injection of lightexposed tryptophan in suckling animals caused a greater elevation of cholylglycine $(39.0 \pm 8.6 \mu \mathrm{M} /$ liter $)$ than freshly prepared tryptophan solutions $(p<0.005)$. Tryptophan and its spontaneous degradation products could contribute to the cholestatic liver changes observed during parenteral nutrition therapy.
\end{abstract}

\section{Abbreviations}

ALT, alanine aminotransferase

ANIT, $\alpha$-naphthylisothiocyanate

AST, aspartate aminotransferase

CCA, conjugates of cholic acid

CG, cholylglycine

TPN, total parenteral nutrition

In 1971, Peden and coworkers (31) reported the occurrence of cholestasis in a premature infant receiving parenteral nutrition. More than 20 subsequent reports have confirmed this observation (2) and have suggested lack of enteral alimentation (4), sepsis (24), and immature hepatic excretory function (35) as possible etiologies. The incidence of cholestasis is related to the duration of parenteral nutrition (1). The rapidity of onset and the severity has been related to the dose of amino acids administered (36). Such observations suggest that amino acids contained in the solutions may be hepatotoxic.

Experimental models utilizing perfused rat liver (15, 32-34), and isolated rat hepatocytes (7) have demonstrated significant cholestatic effects with both individual amino acids and clinically available amino acid solutions. The present investigation was

Received May 6. 1983: accepted February 7, 1984.

Requests for reprints should be addressed to Dr. Russell Merritt, Division of Gastroenterology and Nutrition, Childrens Hospital of Los Angeles, P. O. Box 54700, Los Angeles, CA 90054.

This work was supported by a grant from the J.B. and Emily Van Nuys Foundation. designed to answer the following questions. 1) Can the cholestatic effect of parenterally administered individual amino acids be demonstrated in the intact neonatal rat? 2) Is the cholestasis a dose-dependent phenomenon? 3) Is there an age-dependent sensitivity to the cholestatic effects of parenteral amino acids in the rats? 4) Is a specific hepatotoxic biologic metabolite of a cholestatic amino acid identifiable?

\section{MATERIALS AND METHODS}

Single litters of 1-day-old Sprague-Dawley rat pups were randomized to receive intraperitoneal injections of saline alone (control) or one of 14 single amino acids in saline. Leleiko et al. (22) have previously presented evidence for utilization of intraperitoneally administered amino acids. Amino acids studied were the $l$-forms of tryptophan, valine, histidine, leucine, isoleucine, lysine, threonine, phenylalanine, methionine, arginine, alanine, glycine, serine, and proline (Ajinomoto USA, Inc, Los Angeles). All solutions were freshly prepared and passed through a $0.2-\mathrm{u}$ filter prior to use. Cultures revealed no evidence of bacterial contamination. The various solutions ranged in $\mathrm{pH}$ from 5.5 to 7.0. Each experimental animal received a single daily intraperitoneal injection of $4.0 \mathrm{mM} / \mathrm{kg}$ of a single amino acid in $0.7 \mathrm{ml}$. Control animals received $0.7 \mathrm{ml}$ of normal saline solution. The pups were allowed to nurse freely throughout the study, and the mothers were allowed free access to water and Purina rat chow. Individual litters were housed in single cages in a temperaturecontrolled room at $20^{\circ} \mathrm{C}$ with alternating 12-h light and dark cycles.

After seven days of injections, the pups were fasted for six $h$ starting at $0800 \mathrm{~h}$ and exsanguinated by intracardiac puncture following metaphane anesthesia. Serum was obtained for CG concentration, and liver tissue was placed in $10 \%$ buffered formalin for light microscopy. Liver specimens for electron microscopy were obtained following metaphane anesthesia and whole body perfusion with $2 \%$ glutaraldehyde by left ventricular intracardiac injection following right atrial cardiotomy. In three additional litters given daily injections of either tryptophan (4 $\mathrm{mM} / \mathrm{kg}$ ), leucine $(4 \mathrm{mM} / \mathrm{kg})$, or saline, serum was analyzed for total serum conjugates of CCA. In addition, two litters given daily injections of either tryptophan $(4 \mathrm{mM} / \mathrm{kg})$ or saline had serum obtained for aminotransferases, alkaline phosphatase, and total bilirubin. Animals from two litters also received the $4 \mathrm{mM} /$ $\mathrm{kg}$ tryptophan or saline injection on the 8 th study day at $0800 \mathrm{~h}$ and were then fasted until sacrifice at $1400 \mathrm{~h}$ for determination of serum glucose.

A dose-response curve for tryptophan was determined by randomizing single litters of 1 -day-old rat pups to receive 0 (saline control) $, 1,2,3$, or $4 \mathrm{mM} / \mathrm{kg}$ of tryptophan as a $0.7-\mathrm{ml}$ daily intraperitoneal injection for 7 days. Doses greater than 4 
$\mathrm{mM} / \mathrm{kg}$ could not be studied because of volume and solubility limitations.

The ability of spontaneously formed and commercially available metabolites of tryptophan to elevate rat serum CG was also evaluated. A tryptophan solution was exposed to roof-top sunlight for 7 days and injected as described above. In addition, freshly prepared doses of $4 \mathrm{mM} / \mathrm{kg}$ of commercially available tryptophan metabolites were injected daily for 7 days, except where solubility and injection volume of $0.7 \mathrm{ml}$ dictated a lower dose. The reagents and doses administered (and suppliers) were as follows: kynurenic acid, $4.0 \mathrm{mM} / \mathrm{kg}$; l-kynurenine, $1.3 \mathrm{mM} /$ $\mathrm{kg}$; anthranilic acid, $2.0 \mathrm{mM} / \mathrm{kg}$; tryptamine hydrochloride, 0.8 $\mathrm{mM} / \mathrm{kg}$. 5-hydroxytryptamine, $0.8 \mathrm{mM} / \mathrm{kg}$; /-kynurenine sulfate, $1.3 \mathrm{mM}$; 3-hydroxyanthranilic acid, $0.8 \mathrm{~m} \mathrm{M} / \mathrm{kg}$; xanthurenic acid, $3.8 \mathrm{~m} \mathrm{M} / \mathrm{kg}$; quinolinic acid, $0.8 \mathrm{mM} / \mathrm{kg}$ (all from Sigma Chemical Co., St. Louis, MO); 5-hydroxytryptophan, $0.8 \mathrm{mM} /$ $\mathrm{kg}$ (Aldrich Chemical Co., Milwaukee, WI); and $\mathrm{N}$-formyl- $\mathrm{l}$ kynurenine, $1.5 \mathrm{mM} / \mathrm{kg}$ (Calbiochem, La Jolla, CA). These compounds were used without further purification. After 7 days of injections, the pups were fasted for $6 \mathrm{~h}$ and exsanguinated by intracardiac puncture following metaphane anesthesia. Serum was obtained for CG determination.

The effect of age was examined by obtaining serum for $\mathrm{CG}$ determination in animals who had received single, daily intraperitoneal injections of $4 \mathrm{mM} / \mathrm{kg} / \mathrm{kay}$ of tryptophan for 7,11 , and 14 days following birth. In addition, serum CG levels were obtained in 28-day-old rats following 7 days of intraperitoneal saline injections at a dose of $4 \mathrm{mM} / \mathrm{kg} / \mathrm{d}$. Results at each age were compared to age-matched saline-injected controls.

There were no significant differences among the various groups in the above studies with regard to weight gain or survival during the study. Overall survival was approximately $90 \%$. Any animal with evidence of peritonitis at the time of sacrifice was eliminated from the study. To confirm the ability of serum CG concentration to rise in response to a known cholestatic agent, 28 weanling (21-day-old) rats were randomized to receive a single $0.5-\mathrm{ml}$ intraperitoneal injection containing either $2.5 \mathrm{mg}$ of ANIT, (Eastman Kodak, Rochester, NY) in corn oil or corn oil alone. The substance is a know'n potent cholestatic agent in the rat (21). The animals were sacrificed at 28 and $52 \mathrm{~h}$ following injection, and serum was analyzed for CG. Serum CG concentrations (mean $\pm \mathrm{SD})$ were significantly $(p<0.0005)$ elevated in the ANIT-treated group at both 28 and $52 \mathrm{~h}(100.2 \pm 20.3 \mu \mathrm{M} /$ liter and $67.5 \pm 21.0 \mu \mathrm{M} /$ liter, respectively) compared to corn oilinjected controls $(2.9 \pm 1.2 \mu \mathrm{M} /$ liter and $2.8 \pm 0.5 \mu \mathrm{M} /$ liter $)$. To determine if elevated concentration of serum tryptophan alters serum cholylglycine values as determined by radioimmunoassay, tryptophan was added in concentrations up to $29 \mathrm{mM}$ to rat serum; less than $10 \%$ change in serum CG was observed.

Bile acid determinations. Serum obtained at the time of sacrifice in each experiment was stored at $-20^{\circ} \mathrm{C}$ until the time of analysis. Cholylglycine was determined by a commercially available specific ${ }^{125}$ I-labeled radioimmunoassay (Abbott Diagnostics, North Chicago, IL) (28). Control sera were run with each radioimmunoassay kit. Samples of $25 \mu \mathrm{l}$ of unknown serum or known standards were incubated for $1 \mathrm{~h}$ at room temperature with $200 \mu \mathrm{l}$ of antiserum. Precipitates were obtained by centrifugation at $4200 \times g$ for $15 \mathrm{~min}$ following the addition of $2 \mathrm{ml}$ of $18 \%(\mathrm{w} / \mathrm{v})$ polyethylene glycol. Samples were counted for 1 min in a Searle Analytic 11-85 Gamma Counter. Results were obtained from log-logit curves produced from standard controls. This method has previously been shown to have excellent direct comparability to gas-liquid chromatography (3) and has the added advantage of a very small sample size. This is a mandatory feature of any serum assay to be used in studies utilizing individual neonatal rat pups. Cross-reactivity with taurine-conjugated cholic acid ranged from $15 \%$ (rabbit antibody) to $40 \%$ (porcine antibody) for different kit lots. All but two of the assays performed (for $/$-kynurenine and xanthurenic acid) were done with the rabbit antibody.
Total serum conjugates of cholic acid were determined in Dr. William F. Balistreri's laboratory at the Children's Hospital Research Foundation, Cincinnati, $\mathrm{OH}$, by a previously described radioimmunoassay (3). Serum bilirubin, alkaline phosphatase, alanine and aspartate aminotransferases, and glucose were determined by standard laboratory methods ( 8 ).

Analysis. Results of bile acid determinations (CG and CCA) were expressed as $\mu \mathrm{M} /$ liter (mean $\pm \mathrm{SD}$ except as indicated on figures). Statistical significance was determined by Student's $t$ test.

\section{RESULTS}

Of the 14 amino acids studied, only tryptophan produced significant elevation of serum CG concentration (Fig. 1). Tryptophan-treated animals had a mean CG concentration of $12.8 \pm$ $3.4 \mu \mathrm{M}$ /liter compared to $4.9 \pm 0.9 \mu \mathrm{M}$ /liter in saline-injected controls $(p<0.01)$. When total serum CCA were measured in 8-day-old rat pups that had received 7 days of either tryptophan, leucine, or saline, only the tryptophan group had elevated concentrations. Tryptophan-treated animals had mean total CCA concentrations of $23.3 \pm 11.2 \mu \mathrm{M}$ /liter compared to $6.7 \pm 2.8$ $\mu \mathrm{M} /$ liter in leucine-treated animals and $6.5 \pm 4.2 \mu \mathrm{M} /$ liter in saline injected controls $(p<0.005)$.

A dose-response curve for tryptophan indicated significant elevation of serum CG concentration at doses of $3 \mathrm{mM} / \mathrm{kg} /$ day or higher (Fig. 2). Animals 8 or 12 days old at the time of sacrifice, but not 15-day-old or weanling animals demonstrated elevated CG concentrations following daily intraperitoneal injections of $4 \mathrm{mM} / \mathrm{kg} / \mathrm{d}$ of tryptophan (Fig 3 ).

Standard biochemical tests of liver function revealed only a small statistically significant $(p<0.05)$ elevation of serum ALT in 10 8-day-old tryptophan-treated animals (32.3 $\pm 15.2 \mathrm{IU})$ compared to eight control animals ( $18.4 \pm 11.2 \mathrm{IU})$. Differences for AST (494 \pm 220 versus $338 \pm 152 \mathrm{IU})$ and total bilirubin $(1.2 \pm 0.5$ versus. $0.9 \pm 0.2 \mathrm{mg} / \mathrm{dl})$ were not statistically significant. Serum glucose concentration was equivalent in the treated and untreated animals $(4.37 \pm 0.78 \mathrm{mM}$ /liter versus $4.27 \pm 0.76$ $\mathrm{mM} /$ liter).

Light and electron microscopy of liver tissue failed to demonstrate consistent differences between tryptophan- and salinetreated animals.

Injection of light-exposed tryptophan in the neonatal rat pups resulted in significantly higher serum CG $(39.0 \pm 8.6 \mu \mathrm{M} /$ liter $)$ than the injection of non-light-exposed tryptophan (13.5 \pm 4.8 $\mu \mathrm{M} /$ liter $)(p<0.0005)$. None of the specific tryptophan metabolites tested resulted in significant elevation of serum $C G$ in neonatal animals. Although our preliminary experience suggested that kynurenine and anthranilic acid might be cholestatic (27), daily preparation of fresh solutions of these agents eliminated the apparent cholestatic effect.

\section{DISCUSSION}

This study demonstrated elevation of serum CG, a sensitive indicator of cholestasis, when neonatal rats received $3 \mathrm{mM} / \mathrm{kg} /$ day of tryptophan or light-exposed tryptophan by daily intraperitoneal injection. This phenomenon was not apparent at lower doses of tryptophan or in animals 15 days of age or older at the time of sacrifice. Injection neither of other amino acids present in parenteral nutrition solutions nor biologic tryptophan metabolites resulted in significant elevation of $C G$.

Grant et al (16) first suggested that tryptophan might be related to the hepatic injury which occurs in some adult patients receiving TPN. In their animal studies, mature rats receiving parenteral nutrition solutions containing freshly added tryptophan showed no abnormalities of liver histology, while animals receiving lightexposed tryptophan exhibited steatosis. Our results indicate greater elevation of serum CG with light-exposed tryptophan.

Hepatic perfusion studies using single amino acids, amino acid 


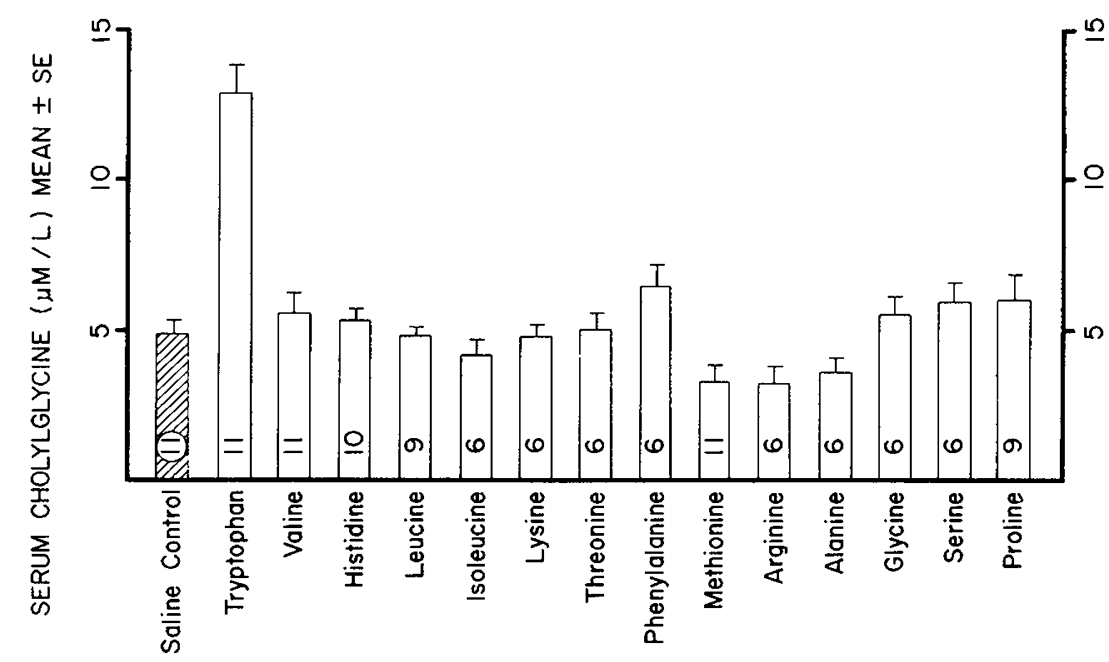

Fig. 1. Effect of intraperitoneal administration of amino acids on serum CG. Four $\mathrm{mM} / \mathrm{kg}$ of the amino acids found in TPN solutions were injected intraperitoneally into neonatal rat pups. Only tryptophan produced a significant $(p<0.01)$ elevation of CG compared to saline control.

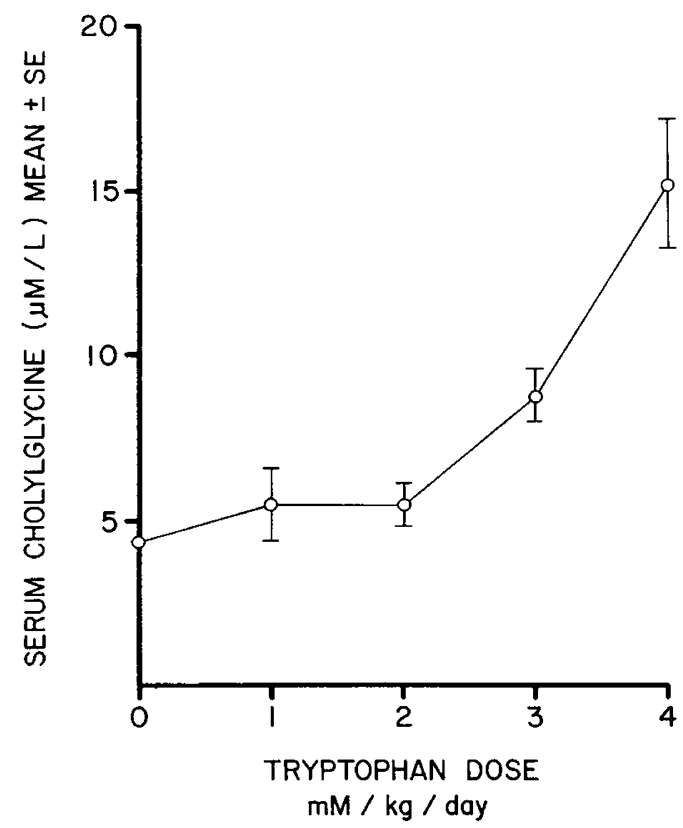

Fig. 2. Dose-related cholestasis effect of tryptophan. Neonatal rat pups were given daily intraperitoneal injections of freshly prepared tryptophan for 7 days. Doses of 3 and $4 \mathrm{mM} / \mathrm{kg}$ resulted in significant elevation $(p<0.0005)$ of serum CG.

analogs, or commercially available amino acid mixtures, have demonstrated decreased bile flow $(15,32-34)$ which is dosedependent $(15,32)$, possibly related to the composition of the amino acid solution (33), and largely the result of apparent inhibition of bile acid-independent bile flow $(33,34)$. Studies in rabbits receiving TPN have demonstrated a greater reduction in bile flow in infant compared to mature animals (37). Damage to the canalicular membrane of the hepatocytes of rabbits receiving TPN was also noted. This finding has also been observed in patients with TPN-associated cholestasis (10).

There are interesting parallels between the cholestatic liver disease observed in infants and the results of our studies in neonatal rats. In both situations, the young (premature) are more susceptible, elevation of serum bile acids is one of the earliest detectable changes (12), and toxicity appears to be dependent upon the dose of amino acids administered. Our observations in neonatal rats given intraperitoneal injections, however, do not approach the clinical complexity of premature newborns receiving parenteral nutrition. The rat pups were allowed to nurse ad

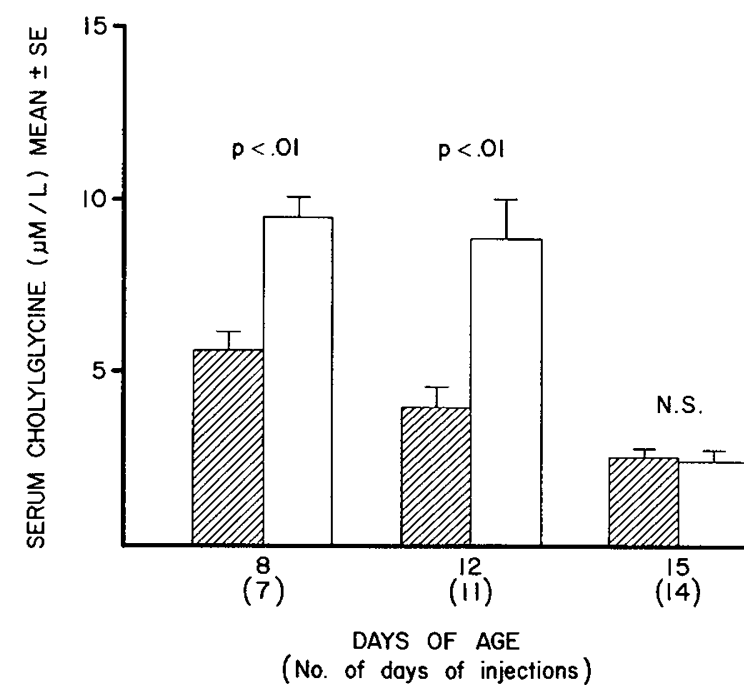

Fig. 3. Age-dependent effect of tryptophan administration. Daily tryptophan injections were started at 1 day of age and animals sacrificed at 8,12 , and 15 days of age. The significant elevation of serum $\mathrm{CG}$ observed at 8 and 12 days of age was no longer apparent at day 15 . Values in parentheses, means \pm SEM.

libitum; i.e., they were not fasted. Sepsis, which may be a contributing factor in the cholestasis seen in the newborn, was presumably not present. In addition, rapid maturation of the rat pup may prevent the development of chronic liver disease in this species. Hepatotoxicity of a given agent may be extremely species-specific, and animal studies may not be directly applicable to human clinical situations.

The ontogeny of activity of tryptophan oxygenase (EC 1.13.11.11) the initial hepatic enzyme in the tryptophan catabolic pathway has been studied in rat pups (17). As adrenalectomy diminishes the late suckling increase in tryptophan oxygenase, and low tryptophan oxygenase activity might be related to susceptibility of neonatal animals to tryptophan-induced cholestasis, we performed adrenalectomies in a group of rat pups at 3 days of age. Tryptophan injections $(4 \mathrm{mM} / \mathrm{kg})$ were continued through day 20 and the animals were sacrificed on day 21 . No differences were noted in the CG concentrations of adrenalectomized versus nonoperated animals.

The single doses of tryptophan employed in our studies are beyond the usual physiologic daily intake. The daily tryptophan intake of the nursed rat can be estimated at approximately 0.37 $\mathrm{mM} / \mathrm{kg} /$ day (calculated from Ref. 6). Our usual study dose adds 
$4 \mathrm{mM} / \mathrm{kg} / \mathrm{day}$, assuming that the entire dose remains within the peritoneal cavity and is absorbed. Breast-fed human neonates receive approxiamtely $0.12 \mathrm{mM} / \mathrm{kg} /$ day of tryptophan (calculated from Ref. 13). Neonates receiving $140 \mathrm{ml} / \mathrm{kg} /$ day of a $2 \%$ amino acid solution daily receive $0.21 \mathrm{mM} / \mathrm{kg} /$ day of tryptophan.

Tryptophan is an amino acid with a number of unique qualities. It is the essential amino acid required in least quantity, it circulates partially bound to albumin in the blood (23), and it can inhibit gluconeogenesis. In addition, tryptophan can affect electrolyte and water absorption from the intestinal lumen $(9$, 25). 5-OH-Tryptamine, a tryptophan metabolite, alters tone of the sphincter of Oddi (2). It is possible that tryptophan may alter bile acid excretion by virtue of its effects on water and mineral transport or as a precursor for 5-OH-tryptamine and its effect on bile duct motility. These possibilities have not been tested directly.

Of special note is tryptophan's sensitivity to degradation on exposure to light. Tryptophan in solutions used for intravenous nutrition has been noted to spontaneously degrade $(19,20,29)$. Intensive light exposure, particularly in the presence of riboflavin. appears to hasten this process (5). Clear tryptophan solutions exposed to bright sunlight or ultraviolet light for a few hours turn brown in color. This browning is probably not due to the Millard reaction, as has been noted in amino acid-dextrose solutions that were heat sterilized, as dextrose was not added to our solutions. Other types of tryptophan degradation products have been previously noted. The brown compounds resulting from photo-oxidation may be related to the enhanced cholestatic effect.

Recent work has demonstrated altered bile composition in TPN patients who developed evidence of hepatotoxicity (14). Increased secondary bile acids, most notably lithocholic acid, have been found. Our study suggests that a preformed component in light-exposed, tryptophan-containing solutions alters bile acid metabolism or excretion. If a component of TPN solution led to increased lithocholic acid formation, lithocholic acid could produce the type of liver injury seen in TPN-associated cholestasis (30), especially in the absence of taurine intake (11). Further in vitro, in vivo, and clinical studies will be required to evaluate this hypothesis.

\section{SUMMARY}

Of the amino acids present in parenteral nutrition solutions, only tryptophan was found to elevate the serum cholylglycine concentrations when injected intraperitoneally into suckling rat pups daily for 7 days. Light-exposed tryptophan was more cholestatic than freshly prepared tryptophan.

Acknowledgments. The authors wish to express their gratitude to Dr. William Balistreri and his laboratory for performing the CCA assay and to Mrs. Evelyn Hsu for the preparation of the manuscript.

\section{REFERENCES}

1. Beale EF, Nelson RM, Bucciarelli RL, Donnelly, WH, Eitzman DV 1979 Intrahepatic cholestasis associated with parenteral nutrition in premature infants. Pediatrics 64:342

2. Behar J. Biancani P 1983 neural control of the sphincter of Oddi: a physiological role of 5 hydroxy-tryptamine in the regulation of basal sphincter of Oddi motor activity in the cat. J Clin Invest 72:551

3. Belknap WM, Balistreri WF, Suchy FJ, Miller PC 1981 Physiologic cholestasis II: Serum bile acid levels reflect the development of the enterohepatic circulation in rats. Hepatology 1:613

4. Benjamin DR 1981 Hepatobiliary dysfunction in infants and children associated with long-term parenteral nutrition: a clinico-pathologic study. Am J Clin Path 76:276
5. Bhatia J, Mims LC. Roesel RA 1980 The effect of phototherapy on amino acid solutions containing vitamins. J Pediatr 96:284

6. Blaxter KC 1961 Lactation and the growth of the young. In: Kon SK, Cowie AT (eds) Milk: The Mammary Gland and Its Secretions. Academic Press, New York, vol 2: 305

7. Blitzer BL. Ratoosh SL $1980 \mathrm{Na}^{+}$-dependent amino acid uptake inhibits hepatic taurocholate uptake: a possible mechanism of amino acid-induced cholestasis. Gastroenterology 79:1005 (abstr)

8. Cheng MH, Lipsey AL, Blanco V, Wong HT, Spiro SH 1979 Microchemical analysis for 13 constituents of plasma from healthy children. Clin Chem 25:692

9. Cooke HJ, Cooke AR 1982 Effect of tryptophan on transport properties of newborn rabbit jejunum. Am J Physiol 242:G308

10. Dahms B. Halpin T 1981 Serial liver biopsies in parenteral nutrition-associated cholestasis of early infancy. Gastroenterology 81:136

11. Dorvil NP. Yousef LM, Roy CC 1983 Taurine prevents cholestasis induced by lithocholic acid sulfate in guinea pigs. Am J Clin Nutr 37:221

12. Farrell MK, Balistreri WF, Suchy FJ 1982 Serum-sulfated lithocholate as an indicator of cholestasis during parenteral nutrition in infants and children. JPEN 6:30

13. Fomon SJ, Filer LJ 1979 Milks and Formulas. In: Foman SJ (ed) Infant Nutrition. Philadelphia, W. B. Saunders Co, p 359

14. Fouin-Fortunet H, Le Quernec L, Erlinger S, Lerebours E, Colin R 1982 Hepatic alterations during total parenteral nutrition in patients with inflammatory bowel disease: a possible consequence of lithocholate toxicity. Gastroenterology 82:932

15. Graham MF, Tavill AS, Halpin TC, Louis LN 1981 The effect of amino acids on bile flow and sodium tacuocholate excretion in the isolated perfused rat liver. Gastroenterology 80:1334 (abstr)

16. Grant JP. Cox CE. Kleinman LM. Maher MM, Pittman MA, Tangrea JA, Brown JH, Cross E. Beazley RM, Jones ES 1977 Serum hepatic enzyme and bilirubin elevations during parenteral nutrition. Surg Gynecol Obstet 145:573

17. Greengard O. Dewey HK 1971 The prematurely evoked synthesis of liver tryptophan oxygenase. Proc Nat Acad Sci 68:1698

18. Hirai Y, Sanada Y, Fujiwara T, Hasegawa S. Kawabara N 1979 High calorie infusion-induced hepatic impairments in infants. JPEN 3:146

19. Jurgens Jr RW, Henry RS, Welco A 1981 Amino acid stability in a mixed parenteral nutrition solution. Am J Hosp Pharm 38:1358

20. Kleinman LM, Tangrea JA, Gallelli JF, Brown JH, Gross E 1973 Stability of solutions of essential amino acids. Am J Hosp Pharm 30:1054

21. Krell H, Hoke H. Pfaff E 1982 Development of intrahepatic cholestasis by alpha-naphthylisocyanate in rats. Gastroenterology 82:507

22. Leleiko NS, Bronstein A. Murphy J, Fox J, Udall J, Suskind R 1977 Intraperitoneal administration of amino acids. JPEN 1:14A (abstr)

23. Lipsett D. Madras BK. Wurtman RJ, Munro HN 1973 Serum tryptophan level after carbohydrate ingestion: selective decline in non-albumin bound tryptophan coincident with reduction in serum free-fatty acids. Life Sci 12:57 (part II)

24. Manginello FP, Javitt NB 1979 Parenteral nutrition and neonatal cholestasis. J Pediatr 94:296

25. Markowitz J, Wapnir RA, Fisher SE 1983 Effect of intraluminal tryptophan on water flux in the perfused rat jejunum. Gastroenterology 84:1240 (abstr)

26. Merritt RJ 1983 Factors affecting cholestasis in infants receiving total parenteral nutrition. In: Lloyd JF. Leathem WD (eds) Parenteral Nutrition in the Infant Patient. North Chicago. Abbott Laboratories, p 63

27. Merritt RJ. Sinatra FR. Henton DH 1982 Cholestatic effect of tryptophan and its metabolites in suckling rat pups. Pediatr Res 16:171 A (abstr)

28. Miller P. Weiss S. Cornell H 1978 Specific ${ }^{125}$ I radioimmunoassay for cholylglycine. Clin Chem 24:999 (abstr)

29. Mirtallo JM, Rogers KR, Johnson JA, Fabri PJ, Schneider PJ 1981 Stability of amino acids and the availability of amino acids in total parenteral nutrition solutions containing hydrochloric acid. Am J Hosp Pharm 38:1729

30. Palmer RH 1972 Bile acids, liver injury and liver disease. Arch Intern Med 130:606

31. Peden VH, Witzleben CL, Skelton MA 1971 Total parenteral nutrition. J Pediatr 78:180

32. Perea A. Tuchweber B, Roy CC. Yousef LM 1981 Intrahepatic cholestasis induced by amino acid solutions for parenteral nutrition in isolated perfused rat liver. Hepatology 1:535 (abstr)

33. Perea A. Tuchweber B, Roy CC. Yousef LM 1982 Decreased bile acid independent flow as a possible cause of amino acids-induced cholestasis. Gastroenterology 82:1258 (Abstr)

34. Preisig R, Rennert O 1977 Biliary transport and cholestatic effects of amino acids. Gastroenterology 73:1240 (abstr)

35. Touloukian RJ, Seashore JH 1975 Hepatic secretory obstruction with total parenteral nutrition in the infant. J Pediatr Surg 10:353

36. Veleisis RA. Inwood RJ, Hunt CE 1980 Prospective controlled study of parenteral nutrition-associated cholestatic jaundice: effect of protein intake. J Pediatr 96:893

37. Zahavi I, Shaffer EA, Gall DG 1982 Total parenteral nutrition (TPN) associated cholestasis in infant and adult rabbits (abstract). Gastroenterology 82:1217 (abstr) 